\title{
AÇÕES EDUCATIVAS EM SAUDE DA CRIANÇA: O BRINCAR ENQUANTO RECURSO PARA PARTICIPAÇÃO DA FAMÍLIA
}

\author{
EDUCATIONAL ACTIONS IN CHILD'S HEALTH: PLAYING AS \\ A RESOURCE FOR FAMILY PARTICIPATION
}

\author{
Regina Zanella Penteado ${ }^{1}$ \\ Mônica Nicolau Seabra ${ }^{2}$ \\ Isabel Maria T. Bicudo-Pereira ${ }^{3}$
}

PENTEADO, R. Z.; SEABRA, M. N.; BICUDO-PEREIRA, I. M. T. Ações Educativas em Saúde da Criança: o Brincar Enquanto Recurso para Participação da Familia. Rev. Bras. Cresc. Desenv. Hum., São Paulo, 6(1/2), 1996.

\begin{abstract}
Resumo: Brincar é uma ação aprendida na relação interpessoal, sendo a principal maneira da criança agir sobre o mundo. Exerce função significativa no processo dinamico de seu desenvolvimento, nos aspectos social, cultural, afetivo, motor, cognitivo, emocional, lingüistico, comunicativo, dentre outros. Neste processo, a familia é o principal interlocutor da criança, servindo de mediador nas relações desta com o mundo.A atividade de brincar tem diferentes sentidos em cada cultura, hábitos e rotina de vida em sociedade. Os profissionais da saúde devem buscar compreender como ocorre o brincar na sociedade atual, os papéis e valores criados a partir do consumo, dos brinquedos industrializamos e das novas formas de interação criança/familia.Cabe ao profissional da saúde auxiliar a familia em seu compromisso educativo com a criança, através de ações educativas em saúde.O brincar é um recurso educativo para a saúde, que pode ser utilizado no envolvimento e ação participativa da familia em práticas de proteção especifica e promoção da saúde da criança.
\end{abstract}

Palavras-chave: promoção da saúde, saúde da criança, educação em saúde, fonoaudiologia, família, brinquedo.

\section{INTRODUÇÃO}

Os três primeiros anos de vida da criança têm significativa importância no processo de desenvolvimento sensorial, motor, cognitivo, lingüístico, afetivo e social. O período compreendido entre o final do primeiro e fim do terceiro ano de vida oferece novos meios à dinâmica do desenvolvimento infantil, com a aquisição da marcha e o acesso à linguagem enquanto meio de expressão e comunicação (AUFAWRE, 1987). Este tempo representa uma fase de organização e forma- ção de hábitos, ainda com sensível dependência familiar.

É a família, não somente enquanto núcleo formado por pai, mãe e filhos, mas compreendida enquanto dinâmica de relações existentes entre a criança e $o$ adulto significativos, que acompanha a trajetória da vida da criança. "Sociologicamente, a família é vista como um agente primário de socialização, ou a primeira unidade social de um ser humano. Psicologicamente, ao prover condições adequadas de cuidados para com as crianças, aparece como condição fundamental

1 Fonoaudióloga do Departamento de Saúde Comunitária do Municipio de Cosmópolis - SP. Mestranda do Departamento de Prática da Faculdade de Saúde Pública- USP.

End.: Av. 6, nº 736, Centro - Rio Claro - SP - CEP 13500-430 - Tel: (019) 524-2748.

2 Terapeuta Ocupacional do Departamento de Saúde Comunitária do Municipio de Cosmópolis - SP. Bacharel em Direito pela PUC-CAMP.

End.: Av. da Saudade, 670 - Vila Kalil Comópolis - SP - CEP 13150-000 - Tel: (019) 872-3487.

3 Profa. Dra. do Departamento de Prática de Saúde Públicada Faculdade de Saúde Pública da USP. End.: Av. Dr. Arnaldo, $7151^{\circ}$ andar, sala 7 - Tel: (011) 3061-5233 R 7743.

4 Entende-se por adulto significativo a pessoa que diretamente relaciona-se com a criança, nos aspectos interativo e afetivo, sendo o responsável pela sua saúde, segurança e educação, independente de consangüinidade ou parentesco. 
para um desenvolvimento psicológico saudável” (GOMES, 1994). Segundo a autora, além de promover a formação das estruturas básicas da personalidade e da identidade, a ação socializadora familiar ensina à criança as diversas "modalidades de aprender".

Segundo ZORZI (1995), a atividade mental infantil depende de sua experiência e atuação sobre objetos, adquirindo significação a partir das relações com o outro. A formação do pensamento, as condutas simbólicas e as significações são construídas pela criança através de sua ação sobre o mundo, mediada pelo outro (ou adulto significativo). É nesta relação que são construídos os significados. A interação, enquanto matriz de significação, é um dos processos constituintes da linguagem, e assim, do sujeito. (FREIRE, 1995). 0 sujeito é, portanto, constituído através da linguagem.

A concepção histórico/social do processo de desenvolvimento e aprendizagem entende o homem como ser social, construíndo o conhecimento a partir da interrelação ativa com o ambiente sociocultural no qual exerce um papel concreto. Os conhecimentos são assim construídos nas e pelas relações interpessoais (socioculturais) e nos diferentes papéis nelas definidos. (Secretaria da Saúde - Rio de Janeiro).

O brincar é uma forma da criança se relacionar com sua circunstância. $\mathrm{O}$ ato de brincar é aprendido e construído na relação interpessoal, sendo através deste que a criança inicia seu processo de autoconhecimento, toma contato com a realidade externa e, a partir de relações vinculares, passa a interagir com o mundo (PIERRI \& KUDO, 1990). Além de expressar as possibilidades que a criança tem de se opor à sua dependência e de adquirir certa autonomia, o brincar também expressa as formas, variadas e construtivas, de relacionar-se com o adulto (LEBOVICI \& DIATKINE, 1985). O brinquedo oferece oportunidade de descobertas, aprendizagem, desenvolvimento da criatividade, sociabilidade, da linguagem, pensarnento, concentração, atenção e expressão. Segundo CUNHA et al. (1988), “o brinquedo é indispensável à saúde física, emocional e intelectual da criança (...) quando bem cultivado, irá contribuir, no futuro, para a eficiência e equilíbrio do adulto”.

Em função de cada povo, cultura, e mesmo das modificações impostas pelos hábitos e rotina de vida em sociedade, a atividade de brincar e o brinquedo têm ocupado diferentes espaços e a eles têm sido atribuídos diferentes sentidos na vida das crianças. Considerar este processo significa buscar conhecer a maneira como o ato de brincar vem se dando na dinâmica familiar de uma socie- dade industrial, e ver a realidade social e cultural em que a criança está inserida.

Assim, preocupados com o desenvolvimento saúde integral da criança, os educadores e profissionais da saúde começam a investir no processo educativo da família, valorizando a atividade de brincar e o brinquedo enquanto recursos educativo, formativo e terapêutico. Além de recurso de trabalho em práticas clínicas/reabilitadoras direcionadas à criança, o brincar pode, também, ser recurso metodológico em trabalhos de Educação em Saúde direcionados a adultos.

No sentido de envolver a família no processo educativo de maneira realmente participativa, os profissionais da saúde podem ainda, visando otimizar sua ação, trabalhar com os adultos significativos buscando despertar sua consciência sobre o ato de brincar enquanto recurso educativo. Os conteúdos referentes à saúde da criança podem ser abordados com os pais através de atividades lúdicas e de brincadeiras que favoreçam discussões de questões sobre saúde, desenvolvimento da criança e aspectos arnplos da educação da família.

Educação para a farnília, segundo GOMES (1994) significa utilizar os recursos desenvolvidos a partir do conhecimento psicológico, sociológico e educacional para assessorar as famílas na sua tarefa de socialização. Acrescenta, ainda, que a educação para família focaliza práticas de socialização dirigidas aos adultos visando seu aprimoramento como educadores.

Considerando esses pressupostos, este trabalho tem por objetivo oferecer aos profissionais da saúde oportunidade de refletirem sobre a importância de brincar como um recurso educativo e de participação da família (adultos significativos); recurso este que poderá ser explorado em práticas coletivas ou grupais de promoção da saúde e proteção específica, na atenção à saúde da criança.

\section{O BRINCAR NA SOCIEDADE ATUAL}

Observando-se a evolução histórica do brinquedo, percebe-se uma gradativa substituição do brinquedo artesanal por outros fabricados industrialmente.

A construção artesanal do brinquedo favorece a criatividade e as transformações e mutabilidades podem ser vivenciadas durante 0 processo de criação e construção da significação que a ele é imputada. Por exemplo, a ação de criar animais como bois, cavalos, eté a partir de alimentos como cenouras, machuchos, batatas, etc; ou utilizar sucatas, como latas, para representar 
panelas, pratos, etc; ou até mesmo transformar um sabugo de milho em uma figura humana, oferece a percepção das diversas etapas de seu processo transformacional.

O ato de brincar já se inicia na elaboração conjunta das diversas fases da fabricação do brinquedo (planejamento do que será feito, relação e coleta de materiais, exercício de projeção imaginária, plasticidade de formas durante sua confecção transformações físicas e funcionais ocorridas, até chegar ao produto final). $\mathrm{O}$ brinquedo artesanal, quando construído em parceria com a criança, favorece a negociação de representações simbólicas e transformações de funções, em uma troca interativa do adulto com o mundo infantil.

Se, no contexto da fabricação artesanal, o brinquedo representava momentos de interação entre criança e adulto e também um elo simbólico entre a criança e a sua realidade de vida prática, na industrialização há um distanciamento de tais referênciais, já que nem adulto nem criança participam das fases de sua construção/fabricação. O brinquedo industrializado já vem com um aspecto e forma física definidos, principalmente quando representa personagens criados e veiculados pela indústria da comunicação (por exemplo, os brinquedos relacionados aos programas televisivos infantis e desenhos animados: Xuxa, Jaspion, Tartarugas Ninjas, Power Rangers, etc), limitando as possibilidades de significação na brincadeira, uma vez que têm funções e ações previamente determinadas por agentes estranhos e desconhecidos - os fabricantes.

Os bonecos e objetos industrializados representam personagens, realidades e culturas, por vezes, muito diferentes da realidade concreta de vida da criança e da família. Os produtos e brinquedos referentes aos programas televisivos infantis são reconhecidos pelas crianças ao relaciona-los aos personagens do programa veiculado. mas dificilmente têm alguma significação para o adulto quando este não acompanha os programas infantis. A pouca experiência do adulto em acompanhar os programas televisivos infantis, e as distinções culturais embutidas na realidade de cada personagem, faz com que este encontre dificuldades em trabalhar simbolicamente com a criança o uso desses brinquedos industrializados. Tais brinquedos podem acabar exercendo uma função de distanciamento, ao invés de recurso de aproximação e participação da criança nos hábitos culturais e sociais de seu contexto de vida. Outro aspecto ainda a ser considerado no brinquedo industrializado é a sua forma e aparência física, cada vez mais próximas ao objeto que representa, tornando-o mais parecido com o objeto real. Esta proximidade com o real acaba por limitar a criati- vidade na brincadeira e restringe a liberdade de transformação e a atribuição de dignificações e representações, contidas no processo de criação do brinquedo artesanal. Exemplificando, a boneca Barbie relaciona-se a todo um conjunto de brinquedos: casa, roupas, carro, acessórios etc, que são verdadeiras miniaturas de objetos reais. Tendo um carro industrializado da boneca a criança já não necessita mais recorrer a sucatas nem a realizar adaptações em outros brinquedos a fim de que sirvam de carro. Desta maneira, a criança passa a ser objeto e não mais sujeito do próprio brinquedo, com expressivo prejuízo para os aspectos criativos, transformacionais e expressivos.

Cabe ainda considerar que, como decorrência da industrialização e comercialização dos brinquedos, inicia-se um processo de subordinação do brincar (enquanto ato, ação lúdica) ao consumo do que é oferecido pelas indústrias e explorado pela mídia. A idéia de entretenimento, diversão, brincar, e o brinquedo enquanto objeto concreto, passam a relacionar-se aos produtos industrializados e necessidades ilusórias são criadas em relação ao seu consumo. À família resta a impressão de que é preciso ter condições/recursos financeiros para adquirir brinquedos industrializados para que a criança possa brincar. Em outras palavras: para brincar é preciso consumir.

Esta associação entre o ato de brincar e o consumo motiva conflitos entre a criança e o adulto, principalmente quando este não dispõe de condições financeiras necessárias à compra do objeto desejado. $\mathrm{O}$ desconforto é nítido quando o adulto relata: "meu filho não brinca porque eu não tenho condição de comprar brinquedos, que são muito caros”. A responsabilidade de brincar com a criança (ou melhor: a justificativa por não brincar) é, assim, deslocada do adulto para o brinquedo industrializado e, deste, para a baixa renda familiar.

A sociedade industrial implica em uma rotina de vida que vem redefinindo papéis familiares, restringindo os momentos de convívio familiar e modificando a relação adulto/criança. A jornada extensa de trabalho fora de casa, as atividades domésticas, os problemas de segurança nos centros urbanos e até mesmo o lazer administrado (assistir às novelas, aos programas de auditório, talk-shows, noticiários) por exemplo, são motivos que os pais encontram para alegar falta de tempo e de condições para brincar com as crianças.

Nas camadas mais pobres da população, a atividade de brincar não tem sido considerada como parte da responsabilidade de educação dos filhos. Brincar com as crianças é uma atividade que tem sido colocada em um plano inferior, interpretado como falta de serviço, perda de tempo 
ou falta de condições financeiras. Assim, sem tempo nem espaço na rotina de vida e relações entre adultos significativos e a criança, a importância do brincar tem sido subestimada.

A redução e/ou inexistência da prática do brincar durante os primeiros anos de vida da criança podem acarretar um déficit no desenvolvimento infantil. Neste caso, é comum a criança apresentar um quadro de atraso no desenvolvimento neuropsicomotor e tarnbém atraso de fala e linguagem. Quadros como estes requerem, na maioria das vezes, a intervenção de profissionais da saúde como fonoaudiólogos, terapeutas ocupacionais, fisioterapeutas, psicólogos, dentre outros, que irão fazer, provavelmente, o que a família deveria e poderia ter feito.

A intervenção dos profissionais da saúde deve dirigir-se à família, a fim de motivar o envolvimento e sua participação responsável no processo educativo da criança. A orientação para que os pais estimulem seus filhos em casa, pode não se tornar efetiva por encontrar, na rotina de vida diária, diversas barreiras. Problemas de organização familiar, da dinâmica de atribuições de papéis e de funções familiares, limites socioculturais, são alguns exemplos de barreiras que podem interferir e dificultar a realização, em casa, do que foi solicitado ou orientado pelo profissional da saúde.

A fim de que seja possível aos profissionais de saúde, através de uma abordagem educativa em saúde, intervir positivamente nas circunstâncias de vida da criança, é indispensável que estes se fundamentem em ações que estejam engajadas na realidade de vida concreta da família. Isso significa contar com uma dinâmica de trabalho que estimule a participação direta da família no processo educativo e que crie condições para a expressão dos adultos significativos (suas preocupações, valores, interpretações, seu contexto cultural e condições de vida).

\section{EDUCAÇÃO EM SAÚDE: O BRINCAR ENQUANTO RECURSO DE PARTICIPAÇÃO}

O conceito de saúde refere-se a um processo complexo que busca compreender o homem frente à sua história, padrões de desenvolvimento, relações com o mundo, ambiente sociocultural, necessidades, direitos e condições de vida. Esta idéia relaciona-se à qualidade de vida, incluindo cidadania, conscientização, condições e nível de vida (FOCESI, 1993 ).
Na atenção à saúde, os programas de promoção da saúde e proteção específica utilizam-se da educação em saúde como um dos principais recursos de ação.

A educação em saúde deve buscar capacitar a população para a reflexão sobre a sua qualidade de vida, causas e prevenção de problemas, possíveis soluções, acesso a recursos, normas e leis existentes, etc. O processo educativo em saúde deve ser iniciado com a criança sob responsabilidade da família, assessorada pela equipe de profissionais da saúde/educação, partilhando responsabilidades (FOCESI, 1993).

Os profissionais da saúde podem utilizarse de espaços comunitários como centros de saúde, creches, escolas infantis, para favorecer o acesso da família às práticas educativas. A proximidade entre o local escolhido como centros das ações e o local de moradia ou trabalho da família é um detalhe importante, já que muitas ações educativas requerem uma continuidade, exigindo freqüência da população a encontros semanais ou quinzenais.

Referindo-se à relação entre profissionais e a família, GOMES (1994) propõe que a atuação do profissional deveria ser no sentido de trabalhar com as possibilidades da família e recursos da comunidade (e não com suas incompetências e dificuldades), numa co-construção de planos de trabalho, da qual participam a família, comunidade e os profissionais. A autora destaca que os procedimentos visam reforçar o sentimento de valor e competência dos pais, encarregados pela sociedade de realizar as tarefas educativas que constituem a socialização primária, sem negar a influência de fatores extrafamiliares, como escolas, redes de saúde ou serviços comunitários.

As práticas educativas em saúde podem ser organizadas de maneira a envolver um grupo de pessoas com interesses e necessidades comuns. A participação da família pode se dar através da formação de grupos (envolvendo mães, pais, avós, ou quaisquer adultos significativos às crianças). Essa oportunidade de compartilhar, com pessoas de outras famílias, alguns problemas e dificuldades de sua rotina de vida, abre espaço para reflexões sobre as diferenças individuais e culturais, as maneiras com que cada indivíduo e cada grupo familiar enfrenta as questões e problemas cotidianos, a percepção dos modelos e valores internalizados por cada indivíduo e, também, a consciência sobre alguns sentimentos, ampliando os recursos e possibilidades de transformação da realidade. Certamente há diferentes maneiras com que cada família encara seu compromisso educativo junto às crianças, bem como os meios que utiliza para efetivá-lo (e em cada família, o 
papel que cada um assume perante a saúde e educação). As experiências e discussões em grupo apresentam a diversidade de maneiras e condições em que se dão as relações entre família e criança; a utilização da ação mediadora do brincar na relação entre o adulto significativo e a criança (e desta com o mundo); a formação dos hábitos da criança (higiene e alimentação); a participação da criança nas atividades domésticas (organização, responsabilidade), por exemplo. Esta diversidade é interessante, pois acrescenta novas idéias e modelos que poderão ser discutidos sob a coordenação do profissional da saúde.

Numa experiência de grupo, através dos relatos dos adultos, é possível realizar um levantamento inicial da rotina de vida da criança e sua família. Tais informações podem evidenciar outros aspectos que passam a fazer parte dos temas de enfoque a serem trabalhados. A partir do relato de um dia comum na vida da criança (desde o momento de acordar, companhias próximas, atividades realizadas, banho, almoço, alimentação, atividades à tarde, jantar, até quando vai se deitar, modo de dormir, etc) podem tornar-se explícitos os conflitos familiares, dificuldades em lidar com limites, relacionamentos afetivos, interativos e comunicativos, as concepções de saúde valores e a maneira da família responder aos eventos da vida.

O profissional de saúde deve estar atento e sensível para perceber o quanto e de que maneira as novas vivências mobilizam a família, discutindo com ela suas reações às diversas situações. É importante, também, levar em consideração a metodologia comunicativa empregada e investigar os melhores canais de expressão e comunicação para a população envolvida, pois a habilidade discursiva (palestras, explicações e orientações) como único recurso pode tornar-se cansativa ou, dependendo das características do grupo envolvido, ser até mesmo um fator desmotivante, provocando o desinteresse e dificultando a participação e envolvimento. Neste sentido, as práticas educativas em saúde devem contar com recursos dinâmicos e criativos que despertem o interesse e estimulem a participação ativa.

Recursos materiais poderão ser utilizados, de maneira que a atuação sobre estes possam simbolizar ou mesmo representar as temáticas discutidas. A proposta de construção conjunta de objetos concretos, relacionados aos temas trabalhados, ao mesmo tempo em que descontrai os adultos participantes, favorece a experiência de vivenciarem, na prática, o brincar enquanto recurso de participação conjunta, interrelação e troca.

A concretização dos temas abordados com os adultos significativos, através da construção conjunta e artesanal de materiais lúdicos (espe- cialmente brinquedos), é um meio de facilitar a compreensão e tomada de consciência das atividades trabalhadas e visualização das transformações ocorridas durante o processo de discussão. Como exemplo de concretização dos temas em materiais lúdicos, podemos citar a construção conjunta de livros (feitos com figuras recortadas de revistas, folhetos e catálogos de propaganda, e coladas em pequenos cadernos) representando eventos rotineiros da criança (durante a discussão de temas como comunicação, alimentação, hábitos de higiene, brincar, etc). Depois de pronto e discutido, o material poderá ser levado para casa e ser utilizado pelos adultos em seus contextos interativos com a criança. Essa experiência prática pode ser um incentivo aos adultos, no momento em que comprova a capacidade de confeccionar materiais lúdicos e brinquedos, servindo de modelo para que possam depois, em parceria com a criança, confeccioná-los artesanalmente em casa.

A construção de brinquedos em grupo, por se tratar de uma atividade mais desconhecida, permite que os adultos sintam-se mais à vontade para trazer ao centro da discussão as questões e dificuldades enfrentadas na rotina de cuidados e de vida da criança. Construir, remodelar e transformar materiais diversos em jogos, livros e brinquedos, atribuindo-lhes distintos sentidos e significados, proporciona aos sujeitos envolvidos uma postura ativa e criativa; que permite abordar com o adulto a percepção de que a realidade não é estática ou imutável e que as pessoas têm condições de oferecer uma nova resposta, diferente e criativa à sua realidade concreta de vida. As vivências em grupo permitem perceber que as diferentes maneiras de enfrentar um mesmo problema são possibilidades reais de, com o apoio de todos, construir novas experiências.

Ao experenciar diferentes possibilidades de abordagem de uma questão, a ação socializadora familliar pode suscitar nas crianças condições mais críticas para enfrentamento de problemas, tendo como referência o comportamento dos pais. Isto torna possível admitir que os problemas não sejam, necessariamente, encarados como ameças, mas, como oportunidades de autosuperação.

\section{CONCLUSÕES}

A atividade de brincar exerce uma função significativa no processo dinâmico de desenvolvimento da criança, a partir do qual se dá a interação com o outro, a atribuição de significados, a construção da linguagem e, através desta, a constituição da criança enquanto sujeito. 
A construção artesanal de brinquedos favorece, entre os pares da brincadeira, a negociação de significados e funções, enquanto estimula a criatividade e a imaginação necessárias ao processo de transformação de objetos do cotidiano em brinquedos.

O brincar pode ser explorado enquanto recurso educativo, direcionado não somente à criança, mas também à família (identificados os adultos significativos àquela criança).

A intervenção educativa em saúde, quando realizada de maneira a envolver a família (adultos significativos) logo nos primeiros anos de vida da criança, pode favorecer a esta melhores condições de vida e de desenvolvimento, num caráter de promoção da saúde e, ao mesmo tempo, prevenir diversos problemas de desenvolvimento motor, de linguagem e fala, social, comunicativo, físico, afetivo, dentre outros, num caráter preventivo de proteção específica.

Para uma abordagem integrativa da saúde da criança é necessário o envolvimento da família, não como espaço para orientações de procedimentos de continuidade do trabalho técnico/profissional já desenvolvido no atendimento terapêutico, mas antes mesmo que as crianças venham a desenvolver problemas ou condições necessárias a uma intervenção clinica; ou seja: o envolvimento da família através da educação participativa, enquanto um espaço aberto para ações educativas em saúde com objetivos mais abrangentes. Assim sendo, a abordagem educativa envolve uma dinâmica de troca, partilha e reciprocidade na construção de elementos significativos, na definição do papel da família e na discussão e abordagem de temáticas a respeito de saúde/educação, estimulando a consciência crítica e participação.

O processo educativo em saúde deve conduzir o adulto à reflexão sobre a sua qualidade de vida, orientando os recursos para enfrentar as dificuldades encontradas. Ao mesmo tempo em que ofereçarn aos participantes condições para a expressão e desenvolvimento da criatividade, os profissionais da saúde devem atentar para os valores e as formas de resistência da família de maneira a conduzi-la para a busca de novas respostas à realidade de vida concreta.

A reflexão a respeito da maneira como está estruturada e organizada a rotina de vida diária pode favorecer maior consciência sobre os valores na sociedade atual. Numa sociedade industrial e de consumo o adulto tende a subestimar e desvalorizar as experiências do brincar que teve em sua infância, marcada por não ter brinquedos industrializados. A partir do momento em que é estimulado a relembrar, relatar e realizar concretamente suas experiências de infância (construir brinquedos, jogos, livros artesanalmente, tal como fizeram em sua infância), o adulto resgata habilidades lúdicas e criativas, que serão transferidas nas atividades de brincar com os filhos.

Cabe ao profissional de saúde auxiliar a família a buscar recursos expressivos e comunicativos com a criança, e neste aspecto, o brincar é o meio educativo para a saúde. A simples orientação para que a família brinque com seus filhos não se torna efetiva, pois pode encontrar barreiras na estruturação da rotina de vida da família, em seus valores, e até mesmo na experiência com $\mathrm{o}$ ato de brincar que os adultos significativos tiveram (ou não) em suas vidas. Assim sendo, muitas vezes, é necessário um trabalho prévio para que os adultos significativos possam experimentar novamente o brincar, resgatando em si próprios o interesse pela atividade, enquanto são apresentados os valores e recursos a serem explorados a partir desta atividade, a fim de que tenham condições de real envolvimento com a criança na ação de brincar.

As estratégias metodológicas que favoreçam vivências educativas em grupo, com os adultos significativos, enriquece as discussões de temáticas de saúde, desenvolvimento e educação, estimulando o senso de responsabilidade, envolvimento e participação ativa. A dinâmica de trabalho grupal e o confronto das diversas realidades de vida (inerentes a cada família), permitem aos adultos envolvidos a oportunidade de vivenciarem novas experiências, resgatarem habilidades e experimentarem diferentes papéis sociais, favorecendo a reflexão e uma atitude criativa sobre sua realidade de vida e sobre sua participação no processo de formação e educação da criança.

É importante que as abordagens educativas em saúde possam contar com o apoio de atividades concretas de construção de materiais que ilustrem, representem ou concretizem as temáticas e objetivos trabalhados, como recursos para facilitar a expressão e a comunicação entre profissionais da saúde e população envolvida.

A construção, em grupo, de materiais de apoio (jogos, livros, brinquedos de sucata) relacionados às temáticas discutidas sob a coordenação do profissional de saúde, pode ser elemento de mobilização, participação e ação, que descobre ou aponta para novos canais interativos entre os profissionais, a família e a criança. 


\begin{abstract}
Anstract: Playing is an action leanned in lhe relationships es^tablished between people, being lhe chief manner children have of acting over the world. It has a signifcant role in lhe dynamic

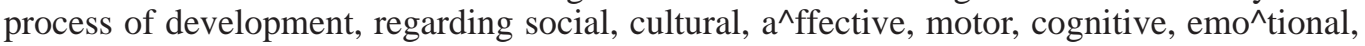
linguistic and communicative aspects, among others. In this process, the family is the main interlocutor of $\mathrm{t}^{\wedge}$ he children, acting as a mediator in the relationships established between them an $\wedge \mathrm{d}$ the world. $\wedge \mathrm{T} \wedge$ he activity of playing $\wedge$ has different meanings in each culture according to habi $\wedge^{\wedge}$ ts and life routine in a society. $\wedge$ Heal ${ }^{\wedge}$ th professionals need to investigate in order to comprehend how playing happens in nowadays sociefies, $\wedge \mathrm{t}^{\wedge} \mathrm{he}$ functions an $\wedge \mathrm{d}$ values associate ${ }^{\wedge} \mathrm{d}$ $\wedge$ to the consumption of industrialized toys, and to the new fonns of interaction between the child an^d the family. In this sense, playing is a concenn to the health pro^fessionals, who mus $\wedge$ t assist $\wedge \mathrm{t} \wedge$ he $\wedge$ family in $\mathrm{i} \wedge$ ts educational compromise with $\wedge$ the child, through educational acfions in health. Playing is an educational resource for developing health; it can ^be used in the involvement and in the cooperative acfion of the $\wedge$ family in pracfices of specific protection and promofion of the child's heal $\wedge$ th.
\end{abstract}

Key-words: health promotion, child's health, health education, speech-language-pathology, family, toys.

\section{REFERÊNCIAS BIBLIOGRÁFICAS}

AUFAUVRE, M. Aprender a Brincar é aprender a viver. São Paulo, Manole, 1987.

BEE, H. A criança em desenvolvimento. São Paulo, Harbra, 1977.

CUNHA, N.H.S.; et al. Brinquedo, desafio e descoberta, subsídios para utilização e confecção de brinquedos. Rio de Janeiro, FAE/MEC, 1988.

ESTATUTO DA CRIANÇA E DO ADOLESCENTE - ECA Planilha para operacionalização (Do Direito à Vida e à Saúde) v. 2. CDH/ CBIA, São Paulo, 1992.

FREIRE, R. M. A linguagem como processo terapêutico. SãoPaulo, Plexus, 1995.

FOCESI, E. Saúde escolar: promoção e educação em saúde - Conferência: III Congresso Médico de Campinas, São Paulo, 9/8/1993. [Mimeo].

COMES, H. S. Educação para família: uma proposta de trabalho preventivo. Rev. Bras. Cresc. Desenv. Hum., 4(1): 34-39, 1994.

L’ABBATE, S. Educação em saúde: uma nova abordagem. Cad. Saúde Públ., 10 (4): 481-490, 1994.

LEBOVICI, S.; DIATKINE, R. Significado e função do brinquedo na criança. Porto Alegre, Artes Médicas, 1985.

LURIA, A. R. Pensamento e linguagem. Porto Alegre, Artes Médicas, 1987.

MENDES, D.; VIANNA, R. Educação em Saúde - Tendências Atuais. In: VIEIRA, R. M.; AVILA, C. R. B. de; VIEIRA, M. M.; PEREIRA, L. D. Fonoaudiologia e saúde pública. Carapicuiba, Pró-Fono, 1995.
MICHILMAN. S. A importância do brinquedo criativo. Terapia ocupacional aplicada à saúde mental e psiquiatria. FCUMG-PUCCAMP. Campinas, 1979. [Mimeo].

PIERRI, S. A.; KUDO, A. M. Brinquedos e brincadeiras no desenvolvimento infantil. In KUDO, A. M; MARCONDES, E; LINS, L.; MORIYAMA, L. T.; GUIMARÃES, M. L. L. G; JULIANI, R. C. T. P; PIERRI, S. A. Fisioterapia, fonoaudiologia e terapia ocupacional em pediatria. São Paulo, Sarvier, 1990.

SECRETARIA DA SAÚDE Programa de saude do escolar numa perspectiva crítica: atenção integral à saúde da criança em idade escolar. Secretaria Municipal da Saúde. Rio de Janeiro.

VASCONCELOS, L.; BOTELHO, A. C; CHIARI, B. M. Orientação a pais de crianças com distúrbio de comunicação - relato de experiência. In. PRO-FONO Ver Atual. Cient. 7 (1) 1995.

ZORZI, J. L. A evolução do simbolismo como base para a compreensão e diagnóstico do retardo de linguagem. Rev. Dist. Comunic., 4 (I) 1991.

ZORZI, J. L. Linguagem e Aprendizagem. In: MARCHESAN, I.Q.; BOLAFFI, C.; GOMES. 1. C. D.; ZORZI, J. L. Tópicos em Fonoaudiologia v. 2. São Paulo, Lovise, 1995.

Recebido em. /9/05/97 Aprovado em: 20/06/97 